\title{
Students' learning preferences and experience in a globalised world: Opportunity to optimise internationalisation in physiotherapy education
}

\author{
Veronika Schoeb $b^{1,2} \&$ Doris Chong ${ }^{1}$ \\ 1. Department of Rehabilitation Sciences, Hong Kong Polytechnic University, Hong Kong, China \\ 2. HESAV - School of Health Sciences, HES-SO University of Applied Sciences and Arts, Western Switzerland, Lausanne, \\ Switzerland
}

Submitted: 01 June 2018 | Accepted: 01 March 2019 | DOI: 10.14426/art/522

\begin{abstract}
Background: Hong Kong is at the cross-road between Eastern and Western cultures. Increasing globalisation allows students to gather experiences from various educational contexts. While internationalisation has been promoted in higher education world-wide, the focus was often put on students from Chinese cultures integrating into Westernised education systems. Not much is known about how students from Chinese background with exposures to Western cultures, reintegrate into a Hong Kong university, characterised by a highly competitive system that potentially affects students' well-being. Aim: To identify learning preferences by Hong Kong physiotherapy students who have been exposed to educational contexts in the USA, Australia or Canada, and to explore their subjective experiences regarding different educational approaches during their studies. Methods: Ten students participated in this phenomenological study. Semi-structured interviews were conducted in English, transcribed 'ad verbatim' and analysed using qualitative content analysis. Findings: Three themes emerged from the data: (1) Interaction between students and teachers, (2) past experiences that help with future dreams, and (3) obstacles and opportunities in learning. Conclusion: Physiotherapy students with globalised experience rely on their past educational exposure to give meaning to their future. They believe that a student-centred approach is crucial for learning. Their experiences shed light on consideration factors for optimally internationalising the physiotherapy curriculum.
\end{abstract}

Keywords: internationalisation, learning preference

Copyright: This work is licensed under a Creative Commons Attribution 4.o International License.

\section{Introduction}

Higher education around the globe including Hong Kong are becoming more and more competitive (Marginson, 2004). It has been shown that university studies are stress-inducing and demanding due to an adjustment of epistemological beliefs, and the need for developing independent learning strategies and self-discipline (Kember, Hong, \& Ho, 2012; Walsh, Feeney, Hussey, \& Donnellan, 2010). As if academic pressure is not already enough to deal with on a daily basis, students are increasingly subject to a more global environment and have more exposure to other education systems. In addition, Asian students studying in Western countries (i.e. USA, Australia, UK) are more frequent compared to the reverse, putting internationalisation at the forefront of higher education's agenda. Internationalisation can be defined as "the intentional process of integrating an international, intercultural or global dimension into the purpose, functions and delivery of post-secondary education, in order to enhance the quality of

Corresponding author:

Veronika Schoeb (veronika.schoeb@hesav.ch)

ORCID: https://orcid.org/oooo-0001-8032-0896

Department of Rehabilitation Sciences, Hong Kong Polytechnic University, Hong Kong, China education and research for all students and staff, and to make a meaningful contribution to society" (De Wit \& Hunter, 2015). In this context, knowledge is to be considered as a process rather than as a product (Kahn \& Agnew, 2017), leading potentially to transformative change (Proctor, 2015). Institutional and disciplinary factors have been identified to play a role for academics to engage in internationalisation, however, it is mainly their own personal or professional experiences within an international context that motivates teachers for this engagement (Proctor, 2015). From a student perspective, the integration of multiple, and often diverse and conflicting, perspectives, is a necessary requirement to achieve global learning (Kahn \& Agnew, 2017). Key foundations for global learning are described as emphasising the "processes of learning, the importance of digging deep into the complexity of the subject matter, thinking about the world relationally through plurality and multiplicity", and by considering self-reflection and interconnected lives as prerequisite for global learning (Kahn \& Agnew, 2017, p. 57). Given these requirements, achieving global learning might be quite an ambitious endeavour for students, teachers and institutions. 


\begin{abstract}
Asian students face challenges particularly in the gloablised learning environment. Commonly reported challenges the Asian students and Western faculty face in light of internationalisation are language barriers, differences in communication styles, differences in teaching and learning styles, as well as social isolation (Wang, Andre \& Greenwood, 2015; Campbell, Strawser \& George, 2016; Newton, Pront \& Giles, 2016). In particular, these authors summarised that Asian students are more used to a teacher-centred approach where they see teachers as the major source of information, and that asking questions is taken as challenging the authority. This belief and style is very different from an approach commonly found in the USA, Australia or Canada where teachers are the facilitators and open discussion is expected in a learning environment. Faculty in these countries particularly stated that they did not feel adequately prepared to take on international students from a different culture, compromising teaching and learning satisfaction both from faculty and students' standpoints (Newton et al., 2016). Clearly, cultural preferences and differences may add another layer of stress to the already stressful higher education environment.
\end{abstract}

On the contrary, there is very limited literature reporting on how students from countries such as the UK or USA adapt to an Eastern-type education environment. One exception is Hardy's experience as a white male student from the United Kingdom studying in Hong Kong (Hardy, Prince \& Worsley, 2015). Apart from the cultural shock in a social environment, the author highlighted the observation that Asian students are generally reserved and unwilling to provide feedback to peers. The reservation described in the article is a typical learning style of Asian students, which is opposite to the Western student-centred approach where discussion amongst peers and between peers and teachers are expected.

Here, we want to emphasise that no one approach is more superior than the other. Ho (2010) explored how Chinese students experienced teaching by local Chinese faculty as compared to foreign faculty (using a Western approach) in a Chinese university. While Chinese students generally perceived Western faculty as more "qualified", they preferred the local Chinese faculty's teaching style, which tends to be more teacher-centred (Ho, 2010). It appears that understanding the various teaching and learning preferences adopted in different cultures is the key to bridge the gap in facilitating learning in a globalised classroom environment.

As anywhere else in the world, in Hong Kong's higher education context, the classroom environment is increasingly more globalised. Not only that there are local Hong Kong students, the number of students from Mainland China and other parts of the world is also on the rise. In physiotherapy, there is also a group of students where they experienced traditional local education, went abroad and then came back to study to become physiotherapists. Their background is unique as they were exposed to various education systems. This uniqueness is not only limited to students, but some faculty as well have this type of education or work background where they have been exposed to different educational cultures. Obviously, how this unique group of students perceive their educational experience in Hong Kong has not been explored.

All in all, competitiveness, expectations and cultural/background differences may all affect students' learning. Students are influenced or mediated by the environment, particularly by cultural factors (group and hierarchical relations, tradition and competition) as well as by contextual factors, such as prior education and tutor behaviour (Frambach, Driessen, Beh, \& van der Vleuten, 2014). Therefore, the aim of this study was to identify learning preferences by Hong Kong physiotherapy Master entry-level students who have been exposed to different educational contexts, and to describe their experiences during their studies, comparing prior and current studies. Findings from this study shed light on how learning is supported and affected in a globalised classroom environment and what needs to happen to promote a positive learning experience. The discussions will surround the current "globalised" situation in physiotherapy education, teachers' roles in a globalised classroom, and strategies to increase awareness in teachers on globalised students' learning needs. Lastly, recommendations at student's, teacher's and institutional level will be suggested.

\section{Methods}

This qualitative study was conducted within a phenomenological framework. Descriptions of subjective experiences (Giorgi, 1997) can provide an understanding of how students give meaning to their educational experience, both abroad and in Hong Kong.

\section{Study context and participants}

The two-year physiotherapy postgraduate entry-level programme is for candidates who previously obtained a bachelor's degree in a related subject (e.g. kinesiology, psychology, nursing, sport sciences). The MPT programme includes foundation subjects (e.g. anatomy, neurosciences), professional subjects (e.g. musculoskeletal or neurological physiotherapy), a final year research project and clinical education. The curriculum ensures that the theoretical subjects (9o credits) and clinical practice (10oo hours) meet the World Confederation for Physical Therapy (WCPT) requirements. Ten second-year Master of physiotherapy (MPT) students (1 female, 9 male) who have previously been exposed to different educational systems (i.e. United States of America, Canada, and Australia) were purposively invited through email or phone to participate in the study. The details of study interests and purposes (the original purposes of exploring wellbeing of internationalised/mature students studying in Hong Kong) were verbally explained to the participants and an information sheet was provided. The ten invited students all agreed to participate in the study. The study was approved by the University's Ethical Review Board (HSEARS 20151126001) and informed consent was obtained from all participants before data collection. Participants were also informed and aware that 
Schoeb, V. \& Chong, D. (2019). Students' learning preferences and experience in a globalised world: Opportunity to optimise internationalisation in physiotherapy education.

additional study objectives may be formulated during data analysis depending on how the data evolved.

\section{Data collection and analysis}

One-on-one semi-structured interviews were conducted in late 2015 by either one of the female authors in their office. No other personnel besides the participant and the researcher were present during the interview. Each participant was interviewed once for about 1 hour and the interview was audio-recorded. The researcher noted down key points during the interview for future references during data analysis. At the time of this study, both authors were faculty members at the Department of Rehabilitation Sciences, The Hong Kong Polytechnic University, and have taught the participants in various subjects in the MPT programme. The first author's highest educational degree is a $\mathrm{PhD}$ while the second author's highest educational degree is a DScPT. They both possessed postgraduate qualitative research training.

Semi-structured interviews are appropriate tools to get an in-depth description of students' social, emotional and physical well-being and their strategies related to educational challenges during their studies (Blanchet \& Gotman, 2005). A one-on-one interview provides the opportunity to explore individual experiences and to obtain insights into perceptions, opinions and beliefs with regard to lived experiences. The value of interview data lies in both their meanings and in how meanings are constructed (Holstein \& Gubrium, 2003) and leads to negotiated, contextually based results (Fontana \& Frey, 2005). An interview guide was prepared in advance in order to make sure that all topics were covered (details included as an appendix in the online version of the article). Since the original purpose of this study was to explore wellbeing of internationalised/mature students studying in Hong Kong, some questions were set to specifically explore stress and coping in this group of participants. However, questions 7 to 13 asked participants their experience (including stress) in both educational systems and responses to those questions allowed researchers to formulate additional objectives on connection of internationalisation, which are the aims of this paper.

The audio-recordings were transcribed 'ad verbatim' and manually analysed using Qualitative Content Analysis (Graneheim \& Lundman, 2004). First, meaning units were summarised into codes; second, categories grouped several codes; and final themes were established by grouping several categories (Graneheim \& Lundman, 2004). See Table 1 for an illustration of analysis.

Both researchers were involved in the process of content analysis (discussion during preliminary analysis, cross-checking of findings). Results including data saturation were discussed among the researchers to ensure thoroughness. No participant requested to read his/her transcript or data results. See additional information on the COREQ (COnsolidated criteria for REporting Qualitative research) checklist for methodology reference in the online version of the article.

\section{Findings}

Three main themes emerged from the data: (1) Interaction between students and teachers, (2) past experiences that help with future dreams, and (3) obstacles and opportunities in learning.

\section{Interaction between students and teachers}

Students talked about their own learning needs and the teachers' style. Feedback from both peers and faculty enhanced participants' learning, however, students were also critical when they talked about teachers' "soft skills". In particular, teachers who were approachable in their interactions with students were more appreciated. In addition, the ability to guide and facilitate students' thinking, to accept differences in opinions, to be patient and accessible were also highly valued soft skills of faculty. They liked to be inspired and motivated by teachers so that learning was enjoyable and self-regulated, as illustrated by the following quotes:

"And once they initiate your interest, you will try to find something online...you will automatically search because they...inspire you" (Interview 5, line 464-468)

“...they would ask you questions to guide you to the right answers.... a good teacher would give us time to think about a problem...offer their views but also open to accept different opinions." (Interview 6, line 621-622, 630-632)

Students treasured to be challenged within a supportive and engaging learning environment.

\section{Past experience and future dreams as physiotherapists}

The students' past work and life experiences enabled them to put things in perspective, and they were not afraid of speaking up or discussing with their teachers, as illustrated by the following quote:

"Because MPT students are a bit older they would basicallythey're better, that's the benefit of mature students is that we're not afraid to speak our mind" (Interview 3, line 415-416)

Speaking up signifies student-centredness and equality between students and teachers. This is a westernised learning style and is more commonly seen in students with globalised experience. The fact that they continue to be more outspoken in an easternised educational context may mean they prefer the westernised style. In addition, participants, as westernised adult learners, pursued their dreams of professional success and felt very passionate about their future as physiotherapists, affecting also their way of learning.

"It actually brings back my passion to become a physiotherapist, definitely have strengthened my goal and also my personality or-and my passion into the profession" (Interview 10, line $30-32$ ) 
Schoeb, V. \& Chong, D. (2019). Students' learning preferences and experience in a globalised world: Opportunity to optimise internationalisation in physiotherapy education.

\begin{abstract}
"I dig in a bit deeper than what they taught us, and I didn't feel like I was wasting my time because it wasn't a requirement by the school, but I felt like it would benefit me for the future anyway" (interview 3, line 249-251)

As continuing education is common in physiotherapy, some students had already planned to specialise in a specific area. The opportunity to experience an overseas clinical placement during their MPT study instilled a wish to work abroad as the following quote illustrates:

them to purposefully formulate and pursue their future goals. However, findings also suggest that learning does not only rely on students' past exposure but also on teachers' pedagogy. The differences in pedagogical approaches between Eastern and Western educational contexts not only impose stress in learning, but also may hinder globalisation of physiotherapy education. Students are becoming more multicultural with a rich experience and background prior to starting physiotherapy education, and this background can enrich their learning if teachers are sensitive to this and appreciate the potential.
\end{abstract}

"I would like to get my license overseas as fast as possible 'cause, after my overseas placement in Canada, and also knowing-after experiencing working environment in Hong Kong, like I felt that, like I would probably end- like work back in, um, Canada and Vancouver in the future" (Interview 6, line 691-694)

\section{Obstacles and opportunities}

As the interviewed students all graduated from an overseas university, they noticed that their previous education was culturally quite different from the one pursued in Hong Kong. In particular, clinical education was perceived as the additional source of stress in Hong Kong. The following quotes illustrate the sometimes strained relationship between mature students and their clinical educators.

"I think she [Clinical Educator] was kind of, like, taking it personally, and I don't think her judgment was that objective" (Interview 8, line 410-411)

Expectations from clinical educators were also not easy to guess, and students had to adapt to different teaching styles and environments all the time.

\section{"It's something-it's some- because for the first clinical} placement, it's not- the stress is more, like, I want to get- like, do better because I don't know what the expectation is. Butlike, for-like, from my-my clinical educator or from my patient. So then it's that I need to get adapted into the environment, it's like a different environment that I (got to adapt)" (Interview 10, line 104-109)

Clinical educators might be less used to global students who are more mature than the local physiotherapy students they usually teach, making it more challenging for them. All in all, the challenges included cultural differences in expectations and styles which created stress in students' studies. The challenges can also be viewed as opportunities and will be discussed in the next section.

\section{Discussion}

Master of physiotherapy students' past diverse educational experiences allow them to communicate with their teachers differently in both academic and clinical education contexts. Their previous participation in other cultural contexts enabled
Prior education exposure influences the way students participate in class. Secondary school education in Hong Kong is characterised by more traditional classrooms, with the exceptions of students attending international schools in Hong Kong (Frambach et al., 2014). A traditional classroom approach in this context not only entails the more one-way lecture style teaching, but also embeds traditional Chinese culture of respecting authority and expecting humbleness from students (Wang et al., 2015). As the majority of undergraduate physiotherapy students come from traditional secondary schools, teachers (including clinical educators) might tailor their approach to these students and not take sufficiently into consideration the internationalised student body (in a Master's entry-level programme). Moreover, although academics appear to understand the concepts of using inquiry-based learning to facilitate learning, this pedagogical approach might hinder academics to cover all the contents in a course, limiting the adoption of this teaching approach commonly used in traditional classrooms like Hong Kong (Chan \& Luk, 2013).

All of our participants had educational experiences in one Western country as well as Hong Kong. From the results of this study, the students' current educational experience had some shortcomings, for example, they noted the lack of inspiring teachers and enabling clinical educators. A Western-type education is characterised by a more student-centred approach where teachers are the facilitators in class, with open discussion and questioning being the norm, and the relationship between students and teachers tends to be more equal (Campbell et al., 2016). This preference is evidently different from the traditional teaching or pedagogical approach in Hong Kong described above. This mismatch in learning and teaching style preferences likely created conflicts and tensions between this group of students and teachers, and hence increased stress in their study.

As our data show, physiotherapy students face challenges in particular during their clinical training periods. Clinical education is a necessary part of allied health professional training (Hobbs, Henley, Higgs, \& Williams, 2000). Clinical education uses clinical settings as teaching platforms and helps students acquire professional skills through different models of clinical education (Lekkas et al., 2007). The model used in Hong Kong in most clinical education sites is based on a single educator working face-to-face with a group of students. The purpose of this is to provide clinical opportunities for students to get experience by integrating their knowledge and skills learnt at school in order to learn how to assess, evaluate and treat clients under the full supervision of a Clinical Educator 
(Hong Kong Polytechnic University, 2012). However, several studies report that clinical education is a moment that can increase stress for students (Walsh et al., 2010; Alzahem, van der Molen, Alaujan, Schmidt, \& Zamkhshary, 2011; Jacob, Itzchak, \& Raz, 2012). The sources of stress include changing from theoretical-based learning to a more interactive and complex environment (Delany \& Bragge, 2009), adapting to a subjective judgment by clinical supervisors (O’Meara, Kostas, Marland, \& Previty, 1994; Hayward, Noonan, \& Shain, 1999; Dyrbye, Thomas, \& Shanafelt, 2005; Jacab et al., 2012; Jacob et al., 2013) and growing into the role of a professional (Monrouxe \& Sweeney, 2013).

No matter the educational context, clinical education is always challenging. In our context, another layer of challenges stems from differences in learning and teaching approaches. Our participants expected open, non-judgmental discussions with clinical educators, value equality and two-way communications. However, this type of behaviour may be perceived as disrespect towards the authority (Wang et al., 2015). As Hong Kong's healthcare system is organized in a hierarchical way (Schoeb, 2016), clinical educators might be more used to being considered as authority. They may not expect this type of learning style from MPT students who are of Chinese origin, hence creating tensions similar to those discussed previously. This tension and stress may further manifest in a placement context because students are in smaller groups, and the student with prior Western educational exposures may be the only one with this background in the group, causing him/her to feel isolated or singled out. These factors warrant serious considerations in the programme as the number of students with globalised backgrounds is increasing, as well as the opportunity that this group of students can bring into the curriculum.

The purpose of internationalisation is to provide opportunities to students for global learning. Global learning competency means that students are able to "shift between identities and angles of understanding" and this so-called "anatomy of perspectives" is central to the process of transformative learning (Kahn \& Agnew, 2017). A curriculum aimed at developing international and intercultural skills, knowledge and attitudes of all students would need to incorporate these dimensions in all aspects of the programme, from preparation, delivery to learning outcomes (Leask, 2009). Furthermore, matching expectations with reality also means to navigate various aspects of this equation: relational approaches, reflection, contextualized knowledge, perspective shifting, disorientation, and responsibility (Kahn \& Agnew, 2017). This study identified MPT students' perspectives of their educational experiences and helps enhance our understanding of the meaning of internationalised physiotherapy students.

\section{Limitations}

This study has a few limitations. The first and main limitation is that this article focuses on a subset of the results. While the original study focused on stress and coping strategies in the studied student population, the focus here was on internationalisation in order to make use of students' reflections and the potential for learning from them. Hence, follow-up interviews might have allowed a deeper investigation of this research question but was not possible as participants had graduated and are practicing physiotherapists now.

Furthermore, as clinical education seemed a crucial learning experience for students on their way to become physiotherapists, the view of clinical educators might have been interesting as well. Furthermore, it would have been interesting to interview local students who were participating in a 4-6 week overseas clinical placement. However, the MPT entry-level programme does only have a very limited offer (four student places) and is very competitive. These limitations, however, might be addressed in a future study.

It should also be noted that the two interviewers had a particular role and relationship with participants, potentially influencing findings in qualitative research. While the first author was educated in a Western educational context only, the second author has a similar profile like the interviewed students: born in Hong Kong of Chinese origin but educated in both Eastern and Western context. These positions from an insider and outsider perspective makes qualitative research more nuanced, as well as more equalized (Chavaz, 2008). Reflexivity throughout the entire research process helps make the impact of these factors more explicit and enhance the quality of this qualitative study (Finlay, 2002).

\section{Implications}

Students and teachers. From this small-scale qualitative study, there is no doubt that the classroom is becoming more globalised with students having various experiences and exposures before joining a physiotherapy programme. We can maximize the potential of the current globalised student population to enhance the "internationalisation at home". This concept is defined as "the purposeful integration of international and intercultural dimensions into the formal and informal curriculum for all students, within domestic learning environments" (Beelen \& Jones, 2015). To foster an environment that achieves these goals, issues need to be tackled at three levels: students, teachers and the institution. This section will provide critical reflection on opportunities for global learning, teachers' role with internationalised students, and strategies to improve awareness of cultural differences.

From the students' level, students with a more Western background should understand that different contexts possess different beliefs and behaviours and these beliefs are not personal. Students could learn to detach a personal emotion from a style and learn to appreciate the positive impacts of a particular teaching style. Coping strategies could be included to help ease their stress when dealing with a "cultural shock" in education. Improving campus support, such as improving students' relationships with administrative personnel and faculty members, could be a way to reduce stress while international students are adapting to a different culture (Hwang \& Wang, 2011). In addition, students can intentionally group themselves with students of other backgrounds/culture in 
Schoeb, V. \& Chong, D. (2019). Students' learning preferences and experience in a globalised world: Opportunity to optimise internationalisation in physiotherapy education.

order to bridge the gap and understand more of what others think (Campbell et al., 2016). The exposure to diversity for both local and internationalised students allows them to step out of their own comfort zones and to stimulate them to become critical thinkers.

In terms of teachers, various strategies have been reported in the literature to improve cultural sensitivities in a globalised classroom. Teachers' training that includes role preparation programmes, programmes to understand various cultures, and programmes to raise awareness of individual differences and needs have been advocated (Ridings, Simpson, Leask, et al., 2008; Campbell et al., 2016; Newton et al., 2016). Practical pedagogical approaches, such as teaching "otherness" (thinking from others' perspectives), becoming "unknowing" (letting go of preconceived ideas), building a caring classroom environment, developing mutual respect and authenticity, developing internal locus of control by problem-solving activities, and instilling fun into classrooms are ways that teachers can teach from a globalised perspective (Ryan \& Dogbey, 2012). At the end of the day, the teachers' tolerance to otherness and diversity and their willingness to make use of diversity as a resource for their classroom will determine whether internationalisation can be accomplished (Otten, 2003). Integrating these mindsets and pedagogies into the curriculum also means to free-up content time and allow for exchange between students. Taking up this opportunity for growth, however, also requires institutional support.

Institutions. As this study explored the students' perspective, it showed that they require support in order to make them aware of cultural differences and to prepare them to expect a mismatch. Awareness is a first step for achieving cultural competence (Ridings et al., 2008). As mentioned before, teachers are at the heart of learning and need to be flexible with regard to the changing student population. Teachers need support in developing their intercultural competence (Ridings et al., 2008) in order to be (a) aware of the needs of the students, (b) to understand their interactions (whether a more hierarchical relations is needed or not), and (c) to reflect and adjust their pedagogy (Frambach et al., 2014). Furthermore, institutional policies are required to set the expectations and verbalize the intended learning outcomes. This would lead to focus on training and support to faculty members to build up not only knowledge regarding internationalisation but also their readiness (Egron-Polak \& Hudson, 2010). All in all, if internationalisation is "the intentional process of integrating an international, intercultural or global dimension into the purpose, functions and delivery of post-secondary education, in order to enhance the quality of education and research for all students and staff, and to make a meaningful contribution to society" (Leask, 2009), we could take advantage of the current globalised student population to enhance 'internationalisation at home'.

\section{Conclusion}

Hong Kong physiotherapy students with exposures to other educational systems perceive that interaction between students and teachers are crucial for their learning. In addition, they continue to rely on their past experiences (especially their globalised learning experience) to help shape their future professional dreams. The findings shed light on the differences inherent to educational cultures and helped identify obstacles and opportunities in learning, as well as essential characteristics of optimal educational experience. This article presented several issues related to three levels - students, teachers and institutions - that need to be tackled in order to optimise the internationalisation of physiotherapy education in Hong Kong.

\section{References}

Alzahem, A. M., van der Molen, H. T., Alaujan, A. H., Schmidt, H. G., \& Zamakhshary, M. H. (2011). Stress amongst dental students: A systematic review. European Journal of Dental Education, 15(1), 8-18.

Beelen, J., \& Jones, E. (2015). Redefining internationalization at home. In A. Curai, L. Matei, R. Pricopie, J. Salmi \& P. Scott (Eds.), The European higher education area: Between critical reflections and future policies. Dordrecht: Springer.

Blanchet, A. \& Gotman, A. (2005). L'enquête et ses méthodes: l'entretien. Paris: Armand Colin.

Campbell, H., Strawser, M. G., \& George, S. (2016).

Communication education and international audiences: Reflections on instructional challenges and pedagogical strategy. Journal of International Students, 6(2), 632-643.

Chan, C. K. \& Luk, L. Y. (2013). Faculty perspectives on the " $3+3+4+$ curriculum reform in Hong Kong: A case study. International Education Studies, 6(4), 56-66.

Chavez, C. (2008). Conceptualizing from the inside: Advantages, complications, and demands on insider positionality. The Qualitative Report, 13(3), 474-494.

Department of Rehabilitation Sciences - Postgraduate Entry Level Studies (2).

Delany, C., \& Bragge, P. (2009). A study of physiotherapy students' and clinical educators' perceptions of learning and teaching. Medical Teacher, 31(9), e402-e411.

De Wit, H. \& Hunter, F. (2015). The future of internationalization of higher education in Europe. International Higher Education, 83, 2-3.

Dyrbye, L. N., Thomas, M. R., \& Shanafelt, T. D. (2005). Medical Student Distress: Causes, Consequences, and Proposed Solutions. Mayo Clinic Proceedings, 8o(12), 1613-1622

Egron-Polak, E., Hudson, R., \& International Association of Universities. (2010). Internationalization of higher education: 
Schoeb, V. \& Chong, D. (2019). Students' learning preferences and experience in a globalised world: Opportunity to optimise internationalisation in physiotherapy education.

Global trends, regional perspectives -- IAU 3rd global survey report. Paris: International Association of Universities.

Finlay, L. (2002). “Outing” the researcher: The provenance, process, and practice of reflexivity. Qualitative Health Research, 12(4), 531-545.

Fontana, A. \& Frey, J. H. (2005). The Interview: From neutral stance to political involvement. In N. K. Denzin \& Y. S. Lincoln (Eds.), The SAGE Handbook of Qualitative Research (3th ed.) (pp.695-727). Thousand Oaks, CA: Sage Publications.

Frambach, J. M., Driessen, E. W., Beh, P. \& van der Vleuten, C. P. M. (2014). Quiet or questioning? Students' discussion behaviors in student-centred education across cultures. Studies in Higher Education, 39(6), 1001-1021.

Giorgi, A. (1997). The theory, practice, and evaluation of the phenomenological method as a qualitative research procedure. Journal of Phenomenological Psychology, 28(2), 235-26o.

Graneheim, U. H. \& Lundman, B. (2004). Qualitative content analysis in nursing research: Concepts, procedures and measures to achieve trustworthiness. Nurse Education Today, 24, 105-112.

Hardy, C., Prince, S., \& Worsley, O. (2015). An innocent abroad: One UK student's experience of studying in Hong Kong and the implications for the international classroom at home. Enhancing Learning in the Social Sciences, 5(3), 30-40.

Hayward, L. M., Noonan, A. C. \& Shain, D. (1999). Qualitative case study of physical therapist students' attitudes, motivations, and affective behaviors. Journal of Allied Health, 28(3), 155-164.

Ho, R. (2010). Assessment of Chinese students' experience with foreign faculty: A case study from a Chinese university. Journal of Teaching in International Business, 21(3), 156-177.

Hobbs, C., Henley, E., Higgs, J., \& Williams, V. (2000) Clinical education program strategies for challenging times. Focus on Health Professional Education: A Multidisciplinary Journal, 2, 1-17

Holstein, J. A. \& Gubrium, J. E. (2003). Inside interviewing: New lenses, new concerns. Thousand Oaks: Sage Publications Ltd.

Hong Kong Polytechnic University (2012). Physiotherapy Programme Structure.

Hwang, K. P. \& Wang, M. (2011). The effects of stressors, living support, and adjustment on learning performance of international students in Taiwan. Social Behavior and Personality, 39(3), 333-344.

Jacob, T., Gummesson, C., Nordmark, E., El-Ansary, D., Remedios, L., \& Webb, G. (2012). Perceived stress and sources of stress among physiotherapy students from 3 countries. Journal of Physical Therapy Education, 26(3), 57-65.

Jacob, T., Itzchak, E. B., \& Raz, O. (2013). Stress among healthcare students-A cross disciplinary perspective. Physiotherapy Theory Practice, 29(5), 401-412.

Kahn, H.K. \& Agnew, M. (2017). Global learning through difference: Considerations for teaching, learning, and the internationalization of higher education. Journal of Studies in International Education, 21(1), 52-64

Kember, D., Hong, C. \& Ho, A. (2012). From model answers to multiple perspectives: Adapting study approaches to suit university study. Active Learning in Higher Education, 14(1), 23-35.

Leask, B. (2009). Using formal and informal curricula to improve interactions between home and international students. Journal of Studies in International Education, 13(2), 205-221.

Lekkas, P., Larsen, T., Kumar, S., Grimmer, K., Nyland, L., Chipchase, L., Jull, G., Buttrum, P., Carr,L., \& Finch, J. (2007). No model of clinical education for physiotherapy students is superior to another: A systematic review. Australian Journal of Physiotherapy, 53(1), 19-28.

Marginson, S. (2004). National and global competition in higher education. Australian Educational Researcher, 31(2), 1-28.

Monrouxe, L. V. \& Sweeney, K. (2013). Between two worlds: Medical students narrating identity tensions. In: C. Figley, P. Huggard, \& C. Rees (Eds.), First do no self harm: Understanding and promoting physician stress resilience. Oxford University Press.

Newton, L., Pront, L.m \& Giles, T. M. (2016). Experiences of registered nurses who supervise international nursing students in the clinical and classroom setting: An integrative literature review. Journal of Clinical Nursing, 25, 1486-1500.

O’Meara, S., Kostas, T., Marland, F., Previty, J. (1994).

Perceived academic stress in physical therapy students. Journal of Physical Therapy Education, 8, 71-75.

Otten, M. (2003). Intercultural learning and diversity in higher education. Journal of Studies in International Education, 7(1), 12-26.

Proctor, D. (2015). Faculty and international engagement: has internationalization changed academic work? International Higher Education, 83, 15-17

Ridings, S., Simpson, L., Leask, B., Freeman, M., Ramburuth, P., Treleaven, L., Sykes, C., \& Fletcher, M. (2008). Developing intercultural competence: ALTC Project Update. HERDSA News, 3o(3), 17-19. 
Schoeb, V. \& Chong, D. (2019). Students' learning preferences and experience in a globalised world: Opportunity to optimise internationalisation in physiotherapy education.

Ryan, J. G. \& Dogbey, E. (2012). Seven strategies for

international nursing student success: A review of the literature.

Teaching and Learning in Nursing, 7, 103-107.

Schoeb, V. (2016). Healthcare service in Hong Kong and its challenges: The role of health professionals within a social model of health. China Perspectives, 4, 51-58.

Walsh, J. M., Feeney, C., Hussey, J., \& Donnellan, C. (2010). Sources of stress and psychological morbidity among undergraduate physiotherapy students. Physiotherapy, 96(3), 206-212.

Wang, C. C., Andre, K., \& Greenwood, K. M. (2015). Chinese students studying at Australian universities with specific reference to nursing students: A narrative literature review. Nurse Education Today, 35, 609-619.

\section{Peer review reports}

Anestis Divanoglou (anestis.divanoglou@gmail.com)

Reviewed: 20 June 2018

Citation: Divanoglou, A. (2018). Students' learning preferences and experience in a globalised world: Opportunity to optimise internationalisation in physiotherapy education. OpenPhysio. DOI: $10.14426 /$ opj/20180620

Anthea Rhoda (arhoda@uwc.ac.za)

Reviewed: 17 September 2018

Citation: Rhoda, A. (2018). Students' learning preferences and experience in a globalised world: Opportunity to optimise internationalisation in physiotherapy education. OpenPhysio. DOI: 10.14426/opj/20180917 